NOV 061989

DE90 002234

\title{
A 14-MeV Beam-Plasma Neutron Source for Materials Testing
}

\author{
A.H. Futch \\ F.H. Coensgen \\ C.C. Damm \\ A.W. Molvik
}

This paper was prepared for submittal to 13th Symposium on Fusion Engineering

Knoxville, TN, October 2-6, 1989

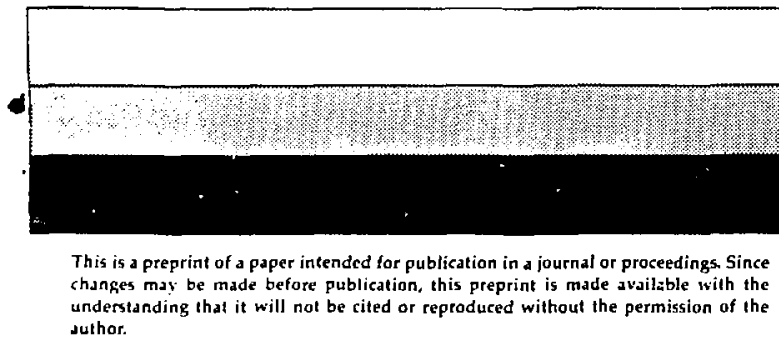

\section{DISCLAIMER}

This report was prepared as an account of wotk sponsored by an agency of the Uniled States Governmen Neither the United Stites Government nor any agency thercof, ror any of their empleyees, makes any warranty, express or implied, or assumes any legal liability or responsibility for t'.e accuracy, completeness, or usefulness of any informalion, apparatus, product, of process disclosed, or repiesents that its use would not infringe privately owned rights. Reference herein to any specific cummercial product, process, or service hy trade name, trademark, manufacturer, or otherwise does not necessarily constitule or imply is endorsement, recom. mendation. or favoring by the United States Govetnment or any agency thereof. The views and opinioits of authors expressed herein do not necessarily state or reflest those of the United States Government of any agency thereol.

\section{MASTER}

DISTRIBUTION OF THIS UOCUMUHT IS URLIMT 


\section{DISCLAISIER}

This document was prepared as an account of work sponsared by an apency of the Inited Stales Government. Vejther the Lniled Stales Governmenl nor the L'nivervity uT California not any of their emplay ets makes any nasranty. express or implied, of assumes any legal liability or responsibility for the accuracy. completenesis, or usefulness of ans information, apparatus. product, or process disclosed, or represents that its use would not intringe prisately owned rights. Reference herein to any specific commercial products, process, or service by teade name, trademark, manufacturef, or otherwise. dues not necessarily constituse of imply its endorsement. secommendation. or favoring by the Linited Stales Goternment or the L'niversity of California. The viexs and opinions oi authors espresed herein do not necessarily state or reflect thrse of the C'nited States Government or the L'niversity of California, and shatl not be used for adiertising ur product endorsement purposes. 


\title{
A 14-MEV BEAM-PLASMA NEUTRON SOURCE FOR MA'TERIALS TESTING
}

\author{
A.H. Futch. F.H. Coensgen, C.C. Danm, and A.W. Molvik \\ Lawrence Livermore Nolional Laboratory \\ P.O. Box 5511, L- 637 \\ Livermorc, CA 9455I
}

\begin{abstract}
The design and performance of $14-M$ HeV beam-plasma ceutron sources for accelerated testing of fusion reactor materibis are described. Continuous production of $14-\mathrm{MfeV}$ neutron fluxes in the range of 5 to $10 \mathrm{M1W} / \mathrm{m}^{2}$ at the plasma surface are produced by D.T reactions in a two-component plasma. In the present designs, $14.11 \mathrm{eV}$ neutrons sesult fron collisions of energetic deuterium ions created by transwetse irjecion of $150 \cdot \mathrm{keV}$ deuterium atoms on a fully ionized tritium target plasma. The beam energy. which is deposited at the center of the tritium column. is transferred to the warm plasma by electron drag, which fluws axially to the end regious. Nevtral gas at high pres5 ute absorbs the enczsy in the tritium plasma and transfers the heat :o the walls of the vacuum vessel. The plasma parameters of the neu. tron source. in timensionless units, have been achieved in the 2XIJB high- 3 plasma. The larger magnetic field of the prese'at d asign permits scaling to the higher eftergy and density of the neutron source cesign. In the extrapolation, care has been taken to preserve the scaling and plaima attributes that contributed to equilibrium, magnetohydrody. namic (MHD) stability, and microstability in $2 \mathrm{XIJB}$. The performance and scaling chiracteristics are described for several designs chosen to enhance the thermal isolation of the two-component plasmas.
\end{abstract}

\section{Introduction}

In this paper we describe several designs for a $14 \cdot \mathrm{MeV}$ neutron source based on the deuterium-tritium (D-T) reaction. In all present designs, the reaclions proceed in a linear two-component plasma pro. duced by transverse injection of $150-k e V$ deuterium atoms into a fully ionized tritium target plasma. Parameters for such a neutron source are selected to meet the requirements for accelerated testing of materials in a fusion materials developmeat program. The overall objective of such a program is to develop new or improved materials with long lives and low activation under $1 \mathrm{H}-\mathrm{MeV}$ neutron irradiation. A plasma-based fusion source would awoid questions of extrapolation because of differ. ences in the neutron energy spectrum and would give valuable design information of synergistic effects in this complex environment.

Fot actelerated malcrials testing, source characteristics must be related to atricipated zeactor goals. The relevant reactor goals are for a mininum neutron wall loading of $3-6 \mathrm{M1} / / \mathrm{m}^{2}$, a minimum firstwid lifetume $6 i^{2}-5 \mathrm{gr}$, and hence a misimum integrated nealron wall

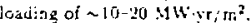

in approactiang a design for a compact. intense neutroh scurce, we revich linetiat systrins lased on high.censity two-component flas. mas. The basic plasma physies of the reaction region is based on the stable operation of the neutral-beam-driven $2 X I I B$ experiment. We first discuss the thermal isolation and power iransport for the "flow" and "rnultiple mirror" models. Finaly we focus on the high-density two-component plasma system with power losses linited by electron thermal conductivity. Our design goal for the high-Auence neutron source was chosen as an uncollided $1.3-3 \mathrm{fl}$ neutron flux equivalent to $10 \mathrm{MWW} / \mathrm{m}^{2}$. to provide the required radiation close for materials lesting in approximately 1-2 yr.

\section{Neutron Source Concepts}

In tle design studies discussed here for beam-plasma neutron sources, D-T nevtrons are produced by injecting a current of encrgetic deuterium atoms into a dense, fully ionized tritium plasma column. As an example. Fig. I shows a schernatic diagram of the neutron source for the electron thermal conductivity case, or Spitzer model. Except for the power transport region, other beam plasma designs are similar. As shown in Fig. 1, the high-density target plasma and the hot deuterium plasma that is formed by ionization of the transverse-injected $D^{\circ}$ current are confined by a linear array of magnets. The usually difficult problem posed by disposal of beam power deposited in the target is solved by conducting the injected power along the plasma column to large area end tanks.

The target plasma is sufficintly dense to stop most of the injected $D^{\circ}$ particles, and it is hot enough (electron temperature $T: \approx 0.2 \mathrm{keV}$ ) to inerease the D-T reaction rate significantly above that obtanned with solid targets. The trapped deuterons cool to the temperatul . of tite tatget plasma and eventually diffuse out the ends of the device. Energy transfer between hot deuterium ions and electrons heats the tritium ions, so the warm-ion temperature $T_{1} \leq T_{c}$ in the plasma column. Evaluations of an optimum beam energy for two-component plasmas have shown a broad maximum to exist at $\sim 200 \mathrm{ke} i{ }^{3}$ Figure 2 shows $Q$. the ratio of fusion power to injection power. as a function of the deuteron injection energy from the paper by Post et al. ${ }^{3}$ For a fixed electron temperature, the maximum value of $Q$ octurs at approximately $200 \mathrm{keV}$. Since the efficiency of positive ion bram terhtirnlogy is adcquate fur ion energies up to $150 \mathrm{keV}$, we lave chesen $150 \mathrm{kel}$ as the injection unergy, thus avoiding the need for an expetisibte and pratracted developn:cul based on negative-ion beams. The feaction rate is decrezsed aholut $20 \%$ by this compr inse.
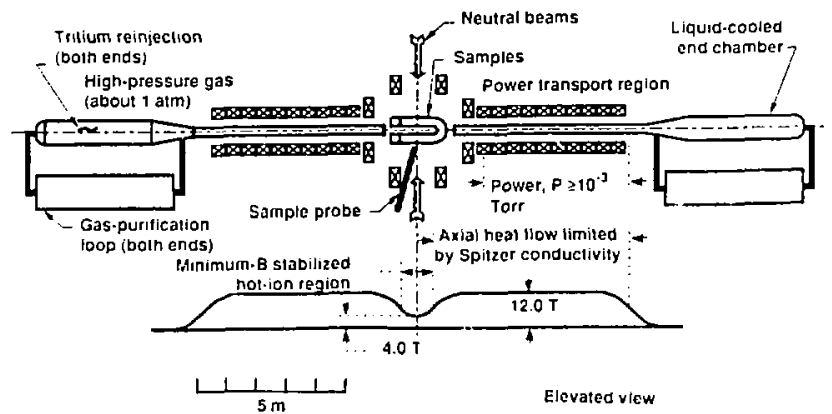

Elevated view

Fig I Schematic of beam plasma neutron soutce. Conteal sectuon of vacuam chamber and neutron bhielding of superconducting magnets ate nol show: 


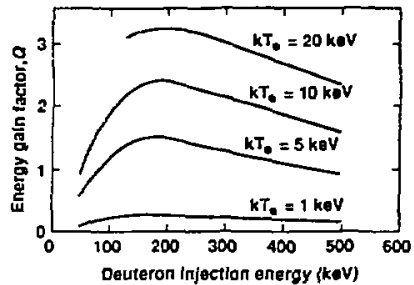

FIG. 2. Enetgy gain fartor $Q$ vs injection energy and electron temperature $T_{c}$ for a mirror ratio $R=10\left(k T_{i}=k T_{e}\right)$.

\section{Reaction Chamber Plasma Mode!}

Because radial density profiles in neutral-beam-driven lincar sys. tems are observed to be Gaussian, we model the plasma with a radial density of the form $n=n e^{-(r / a)^{z}}$, whese $a$ is the $e$-folding distance for the density fall-off. To enhance the plasma density and consequently the reaction rate, we inject the neutral beam off-axis where the plasma density is $n_{c}=\dot{n}_{e} e^{-1}$. To luel the center of the plasma and to minimize the plasma radius, we direct the neutral beam so the $\mathrm{D}^{+}$ions curve toward the axis, as shown in Fig. 3. The magnetic field at the injertion position is chosen so $2 \rho=0$, where $\rho$ is the gyroradius of the hot deuterium ion.

The total plasma density is determined by beam penetration. As a condition for beam penetration with nearly complete beam absorption, we chose ...: line density to the midpoint along the chord through the plasma to be equal to $2 a_{i r a p}^{-1}$ :

$$
\int_{-\infty}^{a} n_{e} d l=\frac{2 \sigma_{\text {trap }}^{-1}}{(1+\delta)}
$$

where $\sigma_{\text {trap }}$ includes beam ionization by electrons and ions as well as rharge-exchange collisions, and $\delta$ is the correction factor for multiplecallision enhancement of :rapping. This condition determines the total plasma density. Figure 3 shows the geometry for pencil beam injection

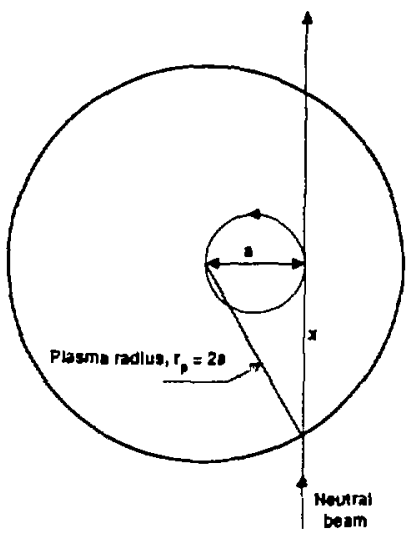

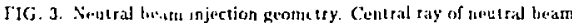

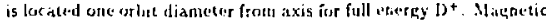
field dirertuon ts rhosen so velority if injected ions is lowidrd plasme chisting along a chord where the electron density $n_{t}=\dot{n}_{e} e^{-\left|\left(a^{2}+r^{2}\right) / s^{2}\right|}$ and the line density is

$$
\int_{-\infty}^{a} n_{e} d l=\bar{n}_{e} \frac{\sqrt{\pi}}{2} e^{-1} \mathbf{c}=0.326 \dot{n}_{e} a .
$$

By equating Eqs. (1) and (2), we find:

$$
\dot{\mathbf{n}}_{e}=\frac{2 \sigma_{\text {(rap }}^{-1}}{0.320 a(1+\delta)} .
$$

The condition for validity of the flow model is that the electron tnean free path $\lambda$ is greater than $t_{c} / 2$; this requirement results in the following expression for the maximun electron density;

$$
\hat{n}_{t}<3 .+\times 10^{23} T_{t}^{2} / l_{c} .
$$

where $I_{c}$ is the full length of the plasma column. The peak hot-ion density is determined from the expression for $\dot{\beta}$ :

$$
\dot{n}_{B}=\frac{\hat{b} B^{2}}{4 \times 10^{-22} E_{A}} \cdot \text { ions } / m^{3} \text {, }
$$

where $E_{h}$ is the average hot-ion energy in beV (determined scparately from a Fokker-Planck code) and $B$ is the magnetic fieid in tesla.

\section{TV. Thermal Isolation and Parallel Power Flow}

\section{A. Flow Model}

If the electron mean free path is longer than the midplane to-mirror distance, then mass tlaw dominatcs over electron thermal conductivity, and the heal flow per unit area, $Q_{f}$, through the magnetic mirrors is

$$
Q_{f}=1 \times 10^{-3} \frac{n_{T} v,}{2} e \frac{m T_{e}}{R} \cdot \mathrm{Ir} \mathrm{W} / \mathrm{m}^{2} \text {, }
$$

with $v$, the sound speed and $\eta=\phi+T$, where $\phi$ is the plasma potential. Both $\phi$ and $T_{e}$ are expressed in keV. W'ith $\varphi \approx 4.3 T_{e}$, and

$$
v_{a}=\sqrt{\left[T_{t}+(5 / 3) T_{1}\right] / m_{h}}=1.77 \times 10^{5} \rho T_{c}^{1 / *} \cdot \mathrm{m} / \mathrm{s} .
$$

where $\rho=\left[1+5 / 3\left(\frac{T_{2}}{T_{*}}\right)\right]^{1 / 3}$ and $m_{h}$ the triton mass, we obtain

$$
Q_{S}=1.42 \times 10^{-17} p n_{J} \tau_{c}^{3 / 2} \eta / R \cdot \mathrm{MW} / \mathrm{m}^{2} .
$$

For a cylindrical plasma of unit cross-sectional area and hot ion length $l_{h}$, the electron drag on the hol deuterium jons is

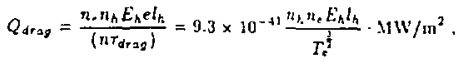

where $n_{e}$ is the total density, $n_{h}$ the hot density. $E_{h}$ the average hotion energy, $e$ the electronic charge, and $(n r)_{d r a g}=1 \times 10^{19} A, T_{e}^{3 / 2}(1 / \ln A)$. Therpfore, for deuterons, where $\ln .1=11.6,(n T)_{\mathrm{drag}}=1.72 \times 10^{18} \mathrm{~J}^{3 / 2}$ \{kel').

Assuming only axial heat loss, we cquite $Q$, $=Q_{\text {dras }}$ on the avis and solve for $\bar{T}_{\text {. }}$ obraining

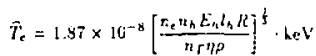

for the prak electron temperature. We entinate $E_{h}$ from the expression

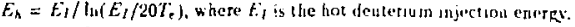

for a Gaussian rindial density profile, the axial powet flow $g_{j}$ becomes

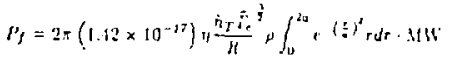

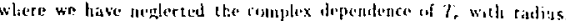
For $a=.095 \mathrm{tm}, \eta=5,3$, ist:d $R=3$,

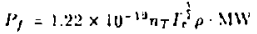


For the low model, the confinement time for warm tritium plasma is not sufficiently long for equilibrium to be established with the electrons. We estimate the tritium ions temperature from analytic equations to be $\approx 0.1 \mathrm{keV}$ for the parameters of Table $I$.

As a check on the simple flow equations discussed here, we have calculated a neutron source casc using the FPPAC multispecies Fokker. Planck code. ${ }^{5}$ For this exanple, the midplanas magnetic field is $4 \mathrm{~T}$, the maguetic misror ratio is $\mathrm{J}, l_{h}=0.15 \mathrm{~m}, l_{c}=1 \mathrm{~m}, \phi / T_{e}$ is set equal to $4.3 . \mathrm{s}_{\mathrm{s}}=1.35 \times 10^{5} \mathrm{~m} / \mathrm{s}, n_{\mathrm{c}}=2.36 \times 10^{21}$, and $n_{h}=1.03 \times 10^{21}$. Table I shows a comparison between the Fokker-Planck code and the simple analytic equations. In general, the agreement is good.

Table I: Comparison of Equilibrium Plasma Parameters from Analytic Equations with Parameters from the FPPAC Fokker-Planck Code.

\begin{tabular}{lcc}
\hline Parameter & Analytic Equations & FPFAC Code \\
\hline$n_{c}$ (electrons $\left./ \mathrm{m}^{3}\right)^{2}$ & $2.36 \times 10^{21}$ & $2.36 \times 10^{21}$ \\
$n_{A}\left(\text { ions } / \mathrm{m}^{3}\right)^{0}$ & $1.03 \times 10^{21}$ & $1.03 \times 10^{21}$ \\
$n_{T}\left(\text { ions } / \mathrm{m}^{3}\right)^{\mathrm{a}}$ & $1.34 \times 10^{21}$ & $1.34 \times 10^{21}$ \\
$T_{e}(\mathrm{keV})$ & 0.40 & 0.38 \\
$E_{h}(\mathrm{keV})$ & 51.0 & 46 \\
$T_{t}(\mathrm{keV})$ & 0.11 & 0.117 \\
$P_{l}(\mathrm{Mll})$ & 50 & 62 \\
$\Gamma\left(\mathrm{MW} / \mathrm{m}^{2}\right)$ & 4.4 & 4.4 \\
\hline
\end{tabular}

All densites aie input parainelets

$\because v^{2}=41 \times 10^{-22} \mathrm{~m}^{2} / \mathrm{s}$

\section{B. Multiple-Mirror Model}

Additional them a jolat.inn may be achieved by the use of muliple mirrors." If the scais tengths are such that

$$
l_{m} \ll \lambda_{e} \ll R I_{c},
$$

where $l_{m}$ is the magnetic ficld scale length and $l_{c}$ is the mirror (all iength. then the pouse sux for a multiple tnirtor is

$$
Q_{t}=1 \times 10^{-3} \frac{n_{T} U_{s}}{2} e \eta \frac{T_{s}}{R}\left[\frac{l_{s}}{L} K\right] .
$$

where $L$ is the total system iength and $K$ is a parameter which varies betwen 1 and 2. approaching 2 for a large number of mirror cells. gives

Solving Eq. (9) for $T_{i}^{*}$ and substituting into the expression for $Q$,

$$
Q !=3.62 \times 10^{-29}\left[\frac{\eta n_{h} n_{c} n_{T} E_{h} l_{h} K l_{C} \rho}{\Omega L}\right]^{\frac{1}{2}} \cdot \mathrm{MW} / \mathrm{m}^{2},
$$

wist $\eta=3.3$. Sisce $Q f=Q_{\text {troj, }}$, the get sesult is chat for the same plasma parameters and wa loading, a multiple-mirror neutron source requres less input power by the factor $\left(K l_{c} / L\right)^{\frac{1}{2}}$.

\section{Conductivity Model}

For the Spizer conductivity model, the power flow $Q_{\text {cand }}$ per unit areia from the curatol polisma to she erds is

$$
\begin{aligned}
& Q \therefore-n=2 K \frac{\partial T_{r}}{\partial Z}
\end{aligned}
$$

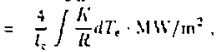

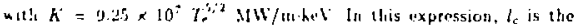

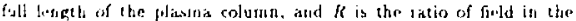
w) Jenotd $B$, wo the curtual field $W$, We use sil units, excen, $T$, is in

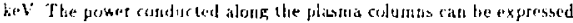

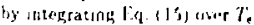

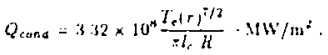

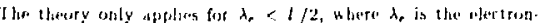
- dectron meritr fece path.

$$
\lambda_{c}=\frac{2 \times 10^{23} T_{e}^{2}}{n_{c} \ln A} \cdot \mathrm{m} .
$$

For $\lambda>l_{c} / 2$, ccllisionless power flow due to the: mal convection is the proper model.

Assuming the power loss $Q_{\text {drag }}$ is by thermal conduction, we can equate this loss to the power input per unit area to the plasma through elertron drag of injected deuterons $\left[\mathbf{E q}\right.$. (9)]. Equating $Q_{\text {cond }}=Q_{\text {dras }}$, we obtain an expression for $T_{e}$ :

$$
T_{e}=2.14 \times 10^{-10}\left(\dot{n}_{h} E_{h} \hat{n}_{e} l_{h} l_{c} R\right)^{1 / 5} e^{-2 / s(+/ a)^{2}}+k \mathrm{cV} .
$$

Now, integrating Eq. (Lfi) over radius to $r_{p}=2 a$, we obtain

$$
P_{\text {cond }} \simeq 2.39 \times 10^{\mathrm{B}} \frac{\widetilde{T}_{c}^{\tilde{c} / 2} \mathrm{a}^{2}}{l_{\mathrm{c}} R} \cdot \mathrm{NW} .
$$

neglecting the power flow for $r>r_{p}$. In our analytic model, we used $\langle\sigma v\rangle$ and $E_{h}$, calculated using the multispecies FPPAC code.

In this paper we emphasize the conductivity model for primarily three reasons. First, the high-density column provides the best isolation between the hot core plasma and the refluxing gas in the end region. At the same time, a slight imbalance between the gas pressure in the two end regions provides sufficjent fueling of the tritium target plasma. The second advartage of the long dense column is that the plasma temperature decreases steadily as the end regions are ap. proached, maintaining a constant plasma pressure as $n_{e}$ increases. Before impacting the end walls, we expect the ions either to recombine into gas atoms of to strike the walls with such low erergy $(<10 \mathrm{cV})^{\mathrm{B}}$ that wall sputtering will not be a problem. The third, and possibly most importart, advantage of the conductivity model is that the arguments for plasma stability, particularly microstability, are more certain because of the dense target plasma present in that case. The busis for stability comes both from theory and from the experience of the 2XIIB experiment. As in 2XIIB, the hot plasma is maintained in a local masnetic field minimum provided by a quadrupole magnet. The neutronsource end cells are designed to absorb the plasma power flowing out of the solenoidal Spitzer region with negligible erosion of the vacuum walls, minimum reflux of wall materials. and a minitnum inventory of tritium. The plasma lieat is removed by expanding the radial walls as the magnetic field lines fan to maintain the power densit:- at the wall below $3 \mathrm{MW} / \mathrm{m}^{2}$; this powes flow is readily removed by consentional water-cooling techniques.

\section{Neutron Source Design}

For a cetailed estimate of the uncollided neutron flux, we assuine the source to be a lincar sourte of ninite iength. The neutron flux o observed at coordinates $r_{1}, i_{1}$ is

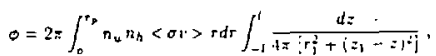

where $z$ is a source cuordinale, extending from -1 to $i$. . Note: $l_{h}=$ 2l, where $l_{n}$ is total sousce lenthth.) Integrating owirs the Gialusian

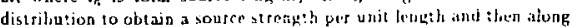
the source length, we uhtain

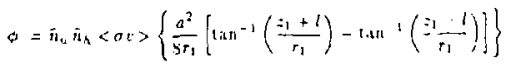

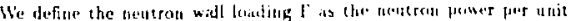
areat of surface at the etridplater $\left(z_{1}=0\right)$ attd at a rodies $r_{1} \geq r_{p}$. ['sing

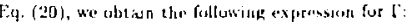

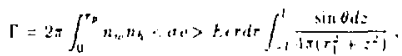

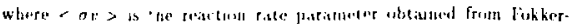

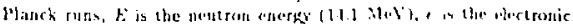

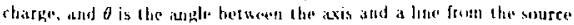

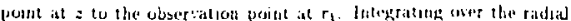


Gaussian density profile and alo.sg the source length, we obtain

$$
\Gamma=1.12 \times 10^{-18} \hat{n}_{w} \hat{n}_{h}\left\langle\sigma v>\left(\frac{a^{2}}{2 r_{1}}\right) \cos \theta_{i} \cdot \mathrm{MW} / \mathrm{m}^{2},\right.
$$

where $\theta_{l}=\theta$ at $z=1$. Note that Eq. (23) is simply the value of $\Gamma$ from the infinite cylindrical model, with the factor $\cos \theta_{l}$ correcting for the finite source length.

\section{A. High-j Design}

With $B_{0}=4 \mathrm{~T}$, a $150 \mathrm{keV} \mathrm{D}$ ion has a gyroradius $\rho=0.020 \mathrm{~m}$, raking a $=2 \rho=0.040 \mathrm{~m}$. For this case, $\sigma_{\text {trap }} \simeq 2.78 \times 10^{-20} \mathrm{~m}^{2}$. With a correction factor. $1+\delta=1.75$. Eq. (3) gives $\hat{\pi}_{\mathrm{c}}=3.2 \times 10^{\mathbf{2 1}} \mathrm{m}^{-3}$. The hot-ion density is determined by the $B$ limit, which for this base case is taken as $\overline{3}=1$ consistent with 2XIIB operation. Thus, neglecting other small contributions to $\beta$,

$$
\hat{n}_{h}=\frac{\hat{3} B^{2}}{4 \times 10^{-22} E_{h}}=8 \times 10^{20} \mathrm{~m}^{-3} .
$$

where $E_{\mathrm{h}}=50 \mathrm{keV}$ as estimated from Fokker-Plancl: calculations. For the hot plasma length, we seletted a value of $l_{h}=0.15 \mathrm{~m}$. This is a compromise to yieid a moderate-sized test volume with good periormance at a reasonable power level and at demonstrated neutral-bean densities.

As seen from Eq. (13), $T_{c}$ can be modestly increased by inercasing the magnitude of the field and the length $l_{\mathrm{r}}$ of the power transport region. We consider the maximum practical field strength $B$, tn be $12 T$, consistent with demonstrated magnet peformance. ${ }^{9}$ We chose $I_{z}=10 \mathrm{~m}$ as a standard length for all cases, since the gain beyond $i_{E}=10 \mathrm{~m}$ is small. The poxer of the injected beam is equal to that lost by conduction and is given by Eq. (19). Parameters for the high-j design are listed in Table II

\begin{tabular}{|c|c|c|c|}
\hline & $\begin{array}{l}\mathrm{High} 3 \\
0.15 \mathrm{~m}\end{array}$ & $\begin{array}{l}\text { Low } \mathrm{i} \\
0.3 \mathrm{~m}\end{array}$ & $\begin{array}{l}\text { Low } 3 \\
0.075 \mathrm{ml}\end{array}$ \\
\hline$D^{\circ}$ beim energy (ket) & 150 & 150 & 150 \\
\hline $\mathrm{D}^{\circ}$ beam pouer (AIW) & 60 & 50 & 13 \\
\hline ! $\left.\mathrm{M}(1 \mathrm{H} / \mathrm{\textrm {J }})^{2}\right)$ & 7.2 & 11.6 & 4.9 \\
\hline Fusion power (All') & 1.0 & 1.1 & 0.17 \\
\hline Plasma (peah) 3 & 1.0 & 0.25 & 0.16 \\
\hline $\bar{n}_{h}(r=0)\left(m^{-3}\right)$ & $8 \times 10^{20}$ & $8 \times 10^{20}$ & $5 \times 10^{22}$ \\
\hline$\hat{n}_{e}\left(r=0, \mathrm{in}^{-3}\right)$ & $3.2 \times 10^{31}$ & $6.3 \times 10^{61}$ & $6.3 \times 10^{21}$ \\
\hline$T_{e}\{r=0 \mid(k c V)$ & 0.22 & 0.21 & 0.14 \\
\hline$E_{n}(\mathrm{kel})$ & 50 & 51 & 16 \\
\hline $\ln (m)$ & 0.15 & 0.30 & 0.075 \\
\hline$a(\pi)$ & 0.0 .4 & 0.02 & 0.02 \\
\hline 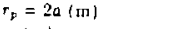 & 0.08 & 0.04 & 0.04 \\
\hline$\rho_{1}(m)$ & 0.02 & 0.01 & 0.01 \\
\hline$l:(\mathbf{m})$ & 10 & 10 & 10 \\
\hline$B_{0}(T)$ & 4 & B & 8 \\
\hline$B,(T)$ & 12 & 12 & 12 \\
\hline Magnel powes r:14i) & 6.8 & 0 & 0 \\
\hline
\end{tabular}

Table 1l: Operating Point Paraneters.

\section{B. Low-i Design}

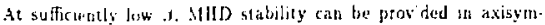
metre linear systrem by ef ponderomotive forces or by providing suffi. cuent perpendicular plasria pressuro in regions of positive curvalure. F!imithating the qiadrupole magnct greatly biniplifies magnet design.

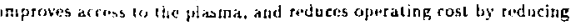

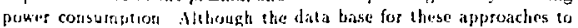

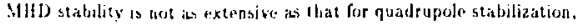
$\mathrm{At}$ is sutfirient to warrist cronsideralion af these systems as neutron

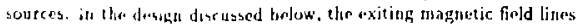

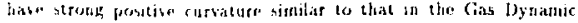

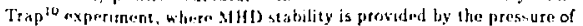

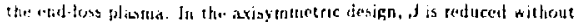

sacrificing plasma density by increasing the magnetic ficld $B_{e}$ to $8 \mathrm{~T}$. At $8 \mathrm{~T}$, the plasma radius $r_{p}$ is redueed from $0.08 \mathrm{~m}$ in the high- $\beta$ design to $0.04 \mathrm{~m}$. With the raduced plasma size the density can be increased to $\hat{n}_{e}=6.3 \times 10^{77} \mathrm{~m}^{-3}$ with adcquate beam penetration. At $8 \mathrm{~T}$ using $50 \mathrm{MIW}$ of beam power, $\Gamma$ at the plasma surface is $160 \%$ that of the $4-\mathrm{T}, 60-\mathrm{NWW}$ design. The $8-\mathrm{T}, 50-\mathrm{MW}$ design also provides a factor of two gain in sample volume and a sedurtion by a factor of four in $\beta$ compared to the $4 . T, 60 . \mathrm{MIW}$ design.

Table IIl gives plasma size and parameter $a$ for one high $-\beta$ design, three low $\beta$ designs, and au earlier accelcrator-hased $D$. Li neutron source. ${ }^{11}$

\section{Summary}

In this paper we have destribed tlie conteptual design of a fusion D. T' neutron source based on plasma physics and technologics developed in the international effrrt to revelop fusion power. Freedom from the requiremem of net power production has permitted the design of a system that is felatively small and low-cost, has low physics tisk, and iequires lictle devplopmert. Because the D- 1 reaction is restricted to a small volume, the volume of activated material and tritium consump. tion are small. The total neution production rate is approximately pyoportional to injpcted beam power and, because the beam system is the latgest cost item. the construction cost increases nearly linearly with the total neutron production.

Acknowledgments. The authors thank T.K. Fowler, D.E. Baldwin. H.L. Berk, and T.C. Simonen for many helpful discussions of the pla:na physics design. A.A. Mirin of the Kational Magnetic Fusion Energy Computer Center provided assistance on the FPPAC FokkerPlanck codes. This work was performed under the auspices of the L.S. Department of Energy by Lawrence Livermore National Laboratory under Contract W-7405-Eng-18.

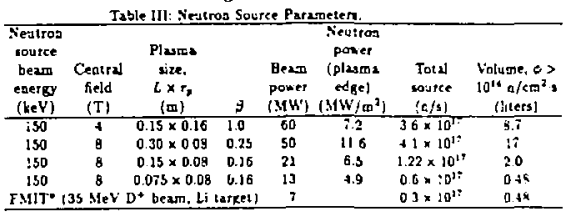

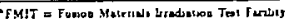

\section{References}

[1] Technical Plonning Activity, Final Report, chapter S, Arganne Ra tional Laboratory, AIgonne. JL, ANL/FPP.87-J (1987).

[2] W.C. Turner et al., Nucl. Fusion, 18, 1011 (1979).

[3] R.F. Post, T.K. Fowler, J. Killeen, and A.A. Mirin, Phys. Rev. Lett, $31,280(1973)$.

[4] C.D. Boley, R.K. Janev, and D.E. Post. Phys. Rètr. Lett., 32, 534 (1984).

[5] M G. M:Coy, A.A. Mirin, and J. Killeen, Comput. Phys. Commun. 24, 3 i (1981).

[6] B.G. Logan, I.G. Drown, and M. A. Lieberman, Ihys. Flutds, 17, 1302 (1974).

[i] L. Spitzer. Jt., Phystcs of Fully Ionized Gases (Intersrience Puhlishers. New Yosk, 1956), 66.

[8] W.L. Hsu, M. Yamada, and I'.J. Busreth, Phys. Rew, Lell., 49. 1001 (1982).

[9] F.H. Coesspen et al., "MF [F' B Accaptance Tests and Operation,"

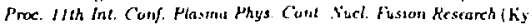
oto, Japan, Novenber $\mid 3-20,19851$.

(10) P.A. Hagryanskit el al, in Prece. Ith tre fonf. Ptasma phys Cont Fusion Resrareh, Kyotn, lago (listernationd Nume tinerpy Agencs, Viesna, 19k71.

[11] R.J. Burkect al., "Super EAIlt an Accoleratof Hased tieutron Source

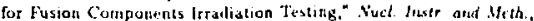
B10/11, 143 (1959). 